Review Article

\title{
Galactose-Induced Skin Aging: The Role of Oxidative Stress
}

\author{
Bauyrzhan Umbayev $\mathbb{D D}^{1}$ Sholpan Askarova, ${ }^{1}$ Aigul Almabayeva, ${ }^{2}$ Timur Saliev, ${ }^{3}$ \\ Abdul-Razak Masoud, ${ }^{4}$ and Denis Bulanin ${ }^{5}{ }^{5}$
}

${ }^{1}$ National Laboratory Astana, Nazarbayev University, Nur-Sultan, Kazakhstan

${ }^{2}$ Astana Medical University, Nur-Sultan, Kazakhstan

${ }^{3}$ S.D. Asfendiyarov Kazakh National Medical University, Almaty, Kazakhstan

${ }^{4}$ Louisiana Tech University, Ruston, Louisiana, USA

${ }^{5}$ School of Medicine, Nazarbayev University, Nur-Sultan, Kazakhstan

Correspondence should be addressed to Bauyrzhan Umbayev; bauyrzhan.umbayev@nu.edu.kz

Received 16 March 2020; Revised 17 May 2020; Accepted 26 May 2020; Published 17 June 2020

Academic Editor: Danina Muntean

Copyright (c) 2020 Bauyrzhan Umbayev et al. This is an open access article distributed under the Creative Commons Attribution License, which permits unrestricted use, distribution, and reproduction in any medium, provided the original work is properly cited.

\begin{abstract}
Skin aging has been associated with a higher dietary intake of carbohydrates, particularly glucose and galactose. In fact, the carbohydrates are capable of damaging the skin's vital components through nonenzymatic glycation, the covalent attachment of sugar to a protein, and subsequent production of advanced glycation end products (AGEs). This review is focused on the role of D-galactose in the development of skin aging and its relation to oxidative stress. The interest in this problem was dictated by recent findings that used in vitro and in vivo models. The review highlights the recent advances in the underlying molecular mechanisms of D-galactose-mediated cell senescence and cytotoxicity. We have also proposed the possible impact of galactosemia on skin aging and its clinical relevance. The understanding of molecular mechanisms of skin aging mediated by $\mathrm{D}$ galactose can help dermatologists optimize methods for prevention and treatment of skin senescence and aging-related skin diseases.
\end{abstract}

\section{Introduction}

Skin aging is a complex process that depends on various extrinsic and intrinsic factors [1]. The most important intrinsic factors of aging include gender, ethnicity, and genetic variations [2]. A number studies on twins have shown a significant inherited component in skin aging [3-5]. Extrinsic factors can be divided into 3 main groups: (1) UV radiation and air pollution; (2) some diseases (e.g., diabetes); and (3) lifestyle choices, such as smoking, alcoholism and nutrition [6-8]. Solar radiation is the most crucial extrinsic factor capable of inducing premature skin aging and skin diseases in exposed areas of the body, e.g., the face and neck $[9,10]$. Smoking and alcoholism can cause skin aging in nonexposed UV areas as well as accelerate aging caused by UV [11].

Among extrinsic factors, nutrition plays a vital role in the development of aging and aging-associated conditions [12]. In fact, an unbalanced diet with the domination of refined carbohydrates has been linked to the development of obesity and obesity-associated metabolic syndrome [13-15], which in turn is associated with diabetes and skin diseases [16], while a balanced nutritional diet helps maintain healthy skin and ensures its normal functioning [17-19]. The results of several studies have demonstrated that skin aging is also associated with a higher dietary intake of carbohydrates [20-22]. It has been established that the primary constructional molecules of the skin, elastin and collagen, can be damaged by carbohydrates via nonenzymatic glycation, the covalent attachment of sugar to a protein, and subsequent production of AGEs [8,23-26], and these processes are closely linked to oxidative stress [27].

Glucose, fructose, and galactose are the essential simple sugars found in our diet. They could be consumed individually or in combination with each other in a form of more complex carbohydrates. The known mechanisms by which carbohydrates cause oxidative stress are the activation of 
mitochondrial oxidative metabolism of glucose, which leads to the generation of reactive oxygen species (ROS). In this case, ROS is generated through mitochondrial respiratory chain enzymes, xanthine oxidases, lipoxygenases, cyclooxygenases, nitric oxide synthases, and peroxidases [28-32]. The enhanced level of mitochondrial ROS leads to the activation of a number of biochemical pathways, such as the polyol pathway [33], the formation of AGEs [34-36], the activation of protein kinase $C[37,38]$, and the hexosamine pathway $[39,40]$, which in turn generate ROS [32]. Fructoseinduced oxidative stress is also underlined by a similar mechanism [41].

There have been a number of debates about the critical role of high serum glucose levels as an "aging accelerator" for the skin [42]. This hypothesis has been supported by recent findings about diabetic and nondiabetic patients demonstrating that elevated levels of glucose can cause the fragmentation of the dermal connective tissue of the skin $[8,21,42]$. However, less attention is given to galactose, although there is data indicating that galactose (in particular, $\mathrm{D}$-galactose or D-gal) is a more powerful glycation agent compared to glucose $[43,44]$ and is capable of inducing oxidative stress $[45,46]$.

Galactose is a C-4 epimer of glucose that combines with glucose to form the disaccharide lactose. There are two enantiomers of galactose: D- and L-galactose. In nature, the main form of galactose is D-gal. The major natural dietary source of galactose is milk and dairy products $[47,48]$. Free galactose is also present in some fruits and vegetables, such as tomatoes, brussels sprouts, bananas, and apples [49]. In addition, the lactose hydrolysate syrup, as a sweetener, has been intensively used in biscuits, confectionery, and some dairy desserts containing high monosaccharide galactose content [48].

Galactose plays an important role in various physiological processes. For instance, it is involved in galactosylation of ceramide during myelin sheath synthesis of Schwann cells (PNS process) and synthesis of heparin/heparan sulfates [50]. It is known that galactose is formed endogenously in the human cells. A $70 \mathrm{~kg}$ adult male could synthesize up to 2 grams of galactose per day $[51,52]$. In general, the possible reaction mechanism of endogenous galactose production is the lysosomal hydrolysis of galactose-containing glycoproteins, glycolipids, and proteoglycans [51, 52]. The level of galactose in the body can be elevated in two cases: (1) via increased consumption of foods rich in galactose, and (2) through metabolic disorders associated with genetic mutations in the enzymes of the Leloir pathway [53].

It was revealed that $\mathrm{D}$-gal is able to trigger aging-like effects in experimental animals [54-57]. In fact, the use of D-gal for animal aging models has been intensively utilized for antiaging research worldwide since the early 1990s [58-60]. Numerous studies have been conducted to assess the aging mechanisms of the brain $[61,62]$ and heart [63] based on a D-gal animal model. Other reports demonstrated that D-gal could also be used for modeling liver [64] and kidney [65] aging. Although there have been a number of studies implicating D-gal-induced skin aging [66-86], the literature on this topic has been scanty and there is a need for these studies to be summarized and analyzed. In this regard, the current review is focused on the changes that occur during D-gal-induced skin aging. It also highlights the recent advances on the underlying molecular mechanisms of Dgal-mediated cell senescence and cytotoxicity.

\section{Galactosemia: Etiology, Clinical Manifestations, and Treatment}

Galactosemia is an inborn genetic metabolic disorder. It emerges as a result of the impaired processing of galactose, which can be subclassified into a few types [87]. It was revealed that the main pathway of galactose metabolism is the Leloir pathway which has several phases (Figure 1) [88].

The first key step is phosphorylation of $\mathrm{D}$-gal by galactokinase (GALK1) to galactose-1-phosphate (Gal-1-P). Next, Gal-1-P is converted to UDP-galactose via D-galactose-1phosphate uridylyltransferase (GALT) using UDP-glucose as the uridine diphosphate source. UDP-galactose $4^{\prime}$-epimerase (GALE) then converts the UDP-galactose to UDP-glucose. UDP-glucose returns into the pathway so that further galactose is converted into glucose-1-phosphate (G1P) and UDPgalactose. Finally, phosphoglucomutase converts the glucose1-P into glucose-6-phosphate.

Classic galactosemia, also known as galactosemia type I, is a severe form of galactosemia that occurs due to the deficiency of GALT. Early manifestations of classic galactosemia are evident in the first few days after birth and initiation of breast-feeding. The most common symptoms are jaundice (74\%), vomiting (4\%), hepatomegaly (43\%), failure to thrive (29\%), poor feeding $(23 \%)$, lethargy $(16 \%)$, diarrhea $(12 \%)$, and sepsis (10\%). Another symptom that usually appears after two weeks as a result of galactitol deposition in the lens is cataract [89]. Later manifestations of the disease include growth delay, neurodevelopment impairments, liver and kidney dysfunctions, and premature mortality [89]. The acute symptoms of classic galactosemia can be resolved by an early implementation of galactose/lactose-restricted diet; however, the patients can still develop long-term complications such as neuropsychiatric impairments and dysfunctions of the ovaries [90].

Galactosemia type II was originally identified as a deficiency of GALK, while type III results from GALE deficiency [87]. The only consequence of GALK deficiency is the development and early onset of juvenile bilateral cataract; however, specific mechanisms underlying this localized-tolenses effect remain unclear. Early diagnosis and treatment of GALK with a galactose-restricted diet may prevent or reverse the formation of cataracts [91].

GALE-deficient galactosemia is presented in three forms: generalized, peripheral, and intermediate. Most patients with GALE deficiency have poor activity of the enzyme in red blood cells (RBCs) and circulating white blood cells but normal or near normal in all other tissues. In the generalized form of the disease, GALE activity is profoundly decreased in all tissues while in intermediate, its form is characterized by deficient enzyme activity in RBCs and white blood cells and less than $50 \%$ of normal levels in other cells. Individuals with peripheral forms of GALE deficiency typically have 

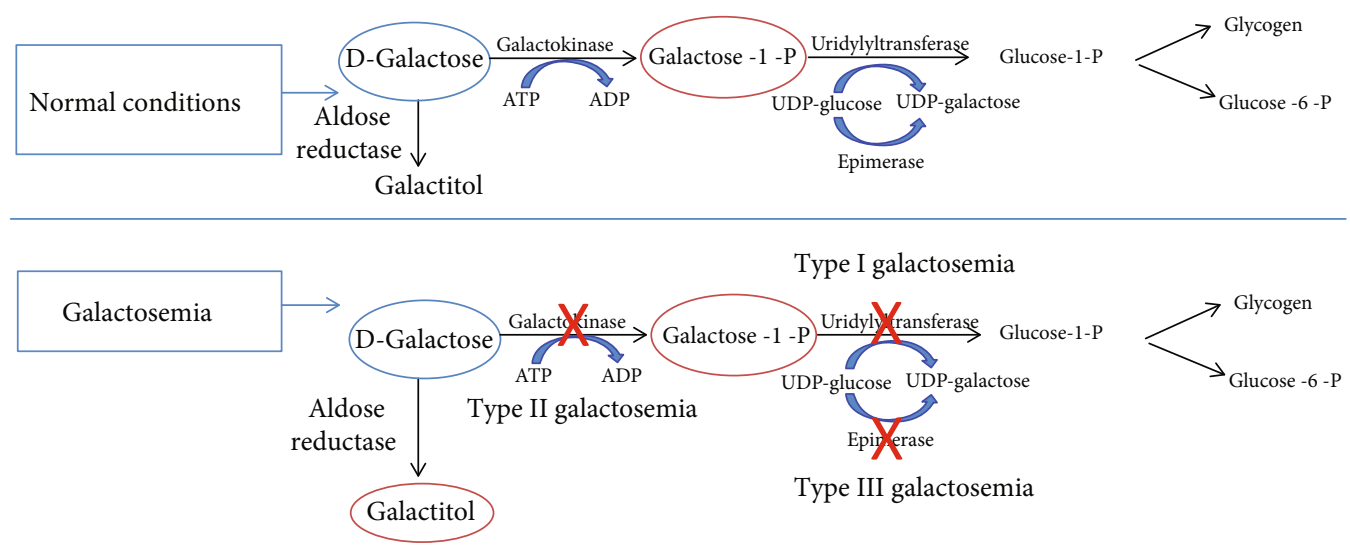

Figure 1: Metabolism of D-galactose.

normal growth and development, whereas patients who have generalized and intermediate forms show symptoms similar to classic galactosemia with different degrees of severity [90].

In addition to the 3 types of galactosemia described above, there may be other forms of this metabolic disorder. For example, the mild variant of classic galactosemia, also known as Duarte galactosemia, is characterized by partial GALT deficiency. This disease is more common than classical galactosemia $(1: 4000)$. Another common variant of galactosemia is the Los Angeles variant of galactosemia with $\mathrm{AAC} \rightarrow \mathrm{GAC}$ transition at nucleotide $\mathrm{C}$, position 940 in exon 10 , leading to an asparagine to aspartate substitution at residue 314 of human GALT enzyme (p.N314D) [92]. It was established that the frequency of p.N314D allele is approximately $11 \%$ in European populations and 8.3\% for panethnic frequency $[92,93]$. Therefore, in this case, the reduction of the GALT enzyme activity is more common and less diagnosed. Given the possibility of high galactose intake with a modern diet coupled with the presence of common variants of galactosemia, an analysis of the possible health effects of elevated galactose levels is necessary.

Although skin abnormalities have not been identified as clinical manifestations of galactosemia, irregular glycosylation of collagen was detected in bones of galactosemic patients [94]. Moreover, increasing experimental evidence, which we discuss in the subsequent sections, suggests that high D-gal concentrations can induce dermal cytotoxicity and aging-like skin changes. Thus, more studies are needed to address skin senescence and senescence-associated skin diseases in patients with galactosemia.

\section{Dermal Toxicity of D-Galactose Studied In Vivo}

We identified 21 publications where D-galactose-induced skin aging in rodents was studied [66-80, 82-86] (Table 1).

In $76 \%$ of these studies, the researchers mainly employed mice ( 16 studies), and only $24 \%$ used rats (5 studies). The most widely utilized mouse and rat strains were Kunming mouse strain (9 publications) and Wistar rats (3 publications). Eleven publications (52\%) used male animals, 5 (24\%) female animals, and 2 (10\%) both genders, and 3 publications (14\%) did not report gender. D-gal doses ranged from 50 to $1000 \mathrm{mg} / \mathrm{kg}$, where D-gal at a dosage of $1000 \mathrm{mg} / \mathrm{kg}$ weight was the most often used in the experiments ( 9 publications). The age of animals varied from 4-6 weeks up to 22 months. The period of exposure was in the range of 30 days to 12 weeks.

These studies showed that significant changes in skin morphology occurred in rodents as a result of D-gal treatment. In particular, the data showed that the administration of D-gal in mice and rats caused skin thinning and worsening of fur quality $[67,68,70,71,74,76-79,82-85]$. Also, hair color changes and unique skin appearance with wrinkles and furrows were detected $[80,84]$ as well as the destruction of hair follicles in the skin $[69,84]$. Tian and colleagues reported the apparent accumulation of subcutaneous fat and fewer cell layers in the skin of Kunming mice treated with D-gal [71]. Wang and coauthors showed that skin tissue angiogenesis was reduced after D-gal administration [76]. The skin moisture level, a known skin aging biomarker, was also decreased in the skin of D-gal-treated animals $[70,74,80]$. In addition, it was reported that the molecular biomarkers of skin aging such as p16 and p21 protein expressions $[83,95]$ were increased, and conversely, the level of sirtuin 1 (Sirt1) and cyclin D1 was reduced in the skin of animals treated by D-gal [74]. However, there are also contradictory results demonstrating that the administration of D-gal at a dose of $125 \mathrm{mg} / \mathrm{kg} / \mathrm{day}$, for 6 weeks, did not change skin water content in male Wistar rats [79].

In majority of the abovementioned studies, special attention was given to the quality of collagen fibers and collagen content $[66-75,78-80,84,86]$. It was established that Dgal treatment reduced the total skin collagen in both mice and rats $[66-75,77-80,84]$ : the type I collagen expression was downregulated $[68,79]$, while the number of type III collagen fibers was increased [68]. The data presented in these studies indicate that significant collagen fiber shortening and disordering occur in D-gal-treated animals [68]. Also, the dermal collagen fibers were sparse, slender, or broken [79]. Disorganization of collagen was noted in a loosely connected network in the skin of rats treated by D-gal [84]. As indicated by Ye et al., a loss of elastin was also observed in the skin of D-gal-treated animals [70]. In addition, the elastic fibers of the skin were reduced, thinned, and scattered in $\mathrm{SD}$ rats [82]. 
TABLE 1: Skin changes induced by D-galactose.

\begin{tabular}{|c|c|c|c|c|c|c|c|}
\hline & Strain & Gender & D-gal doses & $\begin{array}{l}\text { Period of } \\
\text { exposure }\end{array}$ & Age & Aging effects & Ref. \\
\hline \multicolumn{8}{|c|}{ Mice } \\
\hline 1 & C57BL/6J & Female & $\begin{array}{c}50 \mathrm{mg} / \mathrm{kg} \text { daily } \\
\text { subcutaneous injection }\end{array}$ & 8 weeks & 5 months & Skin HYP $\uparrow$ & [66] \\
\hline 2 & $\mathrm{C} 57 \mathrm{BL} / 6 \mathrm{~J}$ & Female & $\begin{array}{l}1000 \mathrm{mg} / \mathrm{kg} \text { daily } \\
\text { subcutaneous injection }\end{array}$ & 8 weeks & 6 weeks & $\begin{array}{c}\text { Dermal thickness } \downarrow \\
\text { Type I collagen fibers } \downarrow \\
\text { Type III collagen } \downarrow\end{array}$ & [67] \\
\hline 3 & C57BL/6J & Male & $\begin{array}{l}1000 \mathrm{mg} / \mathrm{kg} \text { daily } \\
\text { subcutaneous injection }\end{array}$ & 8 weeks & 8 weeks & $\begin{array}{c}\text { Dermal thickness, density } \downarrow \\
\text { p16 } \uparrow \\
\text { MDA } \uparrow \\
\text { SOD } \downarrow \\
\text { CAT } \downarrow \\
\text { GSH-Px } \downarrow\end{array}$ & [83] \\
\hline 4 & $\begin{array}{l}\text { Kunming } \\
\text { mice }\end{array}$ & $\begin{array}{l}\text { Not } \\
\text { reported }\end{array}$ & $\begin{array}{l}1000 \mathrm{mg} / \mathrm{kg} \text { daily } \\
\text { subcutaneous injection }\end{array}$ & 6 weeks & $\begin{array}{c}22 \\
\text { months }\end{array}$ & $\begin{array}{c}\text { Collagen } \downarrow \\
\text { Dermal thickness } \downarrow \\
\text { Collagen fibers are shorter, less compact, } \\
\text { and more disordered } \\
\text { Type I collagen fibers } \downarrow \\
\text { Type III collagen fibers } \uparrow\end{array}$ & {$[68]$} \\
\hline 5 & $\begin{array}{l}\text { Kunming } \\
\text { mice }\end{array}$ & Male & $400 \mathrm{mg} / \mathrm{kg}$ intraperitoneally & 30 days & 8 weeks & $\begin{array}{c}\text { Destruction of hair follicles in skin } \\
\text { Skin HYP } \downarrow\end{array}$ & [69] \\
\hline 6 & $\begin{array}{l}\text { Kunming } \\
\text { mice }\end{array}$ & $\begin{array}{l}\text { Male and } \\
\text { female }\end{array}$ & $\begin{array}{l}1000 \mathrm{mg} / \mathrm{kg} \text { daily } \\
\text { subcutaneous injection }\end{array}$ & 42 days & 6 weeks & $\begin{array}{c}\text { SOD } \downarrow \\
\text { MDA } \uparrow \\
\text { Skin HYP } \downarrow \\
\text { Elastin } \downarrow \\
\text { Skin moisture } \downarrow \\
\text { Dermal thickness } \downarrow \\
\text { Collagen } \downarrow \\
\text { HYP } \downarrow\end{array}$ & [70] \\
\hline 7 & $\begin{array}{l}\text { Kunming } \\
\text { mice }\end{array}$ & Male & $\begin{array}{l}150 \mathrm{mg} / \mathrm{kg} \text { daily } \\
\text { intraperitoneally }\end{array}$ & 6 weeks & Unknown & $\begin{array}{c}\text { Dermal thickness } \downarrow \\
\text { HYP } \downarrow\end{array}$ & [71] \\
\hline 8 & $\begin{array}{l}\text { Kunming } \\
\text { mice }\end{array}$ & Female & $\begin{array}{c}1000 \mathrm{mg} / \mathrm{kg} \text { daily } \\
\text { subcutaneous injection }\end{array}$ & 42 days & 3 months & $\begin{array}{c}\mathrm{MDA} \uparrow \text { and GSH-Px } \uparrow \\
\mathrm{HYP} \downarrow\end{array}$ & [72] \\
\hline 9 & $\begin{array}{l}\text { Kunming } \\
\text { mice }\end{array}$ & Female & $\begin{array}{l}1000 \mathrm{mg} / \mathrm{kg} \text { daily } \\
\text { subcutaneous injection }\end{array}$ & 30 days & 8 weeks & $\begin{array}{c}\mathrm{CAT} \downarrow \\
\mathrm{SOD} \downarrow \\
\mathrm{GPH}-\mathrm{Px} \downarrow \\
\mathrm{HYP} \downarrow \\
\mathrm{MDA} \uparrow\end{array}$ & [73] \\
\hline 10 & $\begin{array}{l}\text { Kunming } \\
\text { mice }\end{array}$ & Male & $\begin{array}{l}200 \mathrm{mg} / \mathrm{kg} \text { daily } \\
\text { subcutaneous injection }\end{array}$ & 8 weeks & 6 weeks & $\begin{array}{c}\mathrm{H}_{2} \mathrm{O}_{2} \uparrow \\
\mathrm{MDA} \uparrow \\
\mathrm{CAT} \downarrow \\
\mathrm{GSH} \downarrow \\
\mathrm{GSH}-\mathrm{Px} \downarrow \\
\text { Dermal thickness } \downarrow \\
\text { Skin integrity and hair follicles were also } \\
\text { impaired } \\
\text { Collagen } \downarrow \\
\text { Skin collagen fiber content is reticular, more } \\
\text { loose, and irregular }\end{array}$ & [84] \\
\hline 11 & $\begin{array}{l}\text { Kunming } \\
\text { mice }\end{array}$ & Male & $\begin{array}{l}500 \mathrm{mg} / \mathrm{kg} \text { daily } \\
\text { intraperitoneally }\end{array}$ & 8 weeks & Unknown & $\begin{array}{c}\text { Skin moisture } \downarrow \\
\text { HYP } \downarrow \\
\text { Dermal thickness } \downarrow \\
\text { Collagen } \downarrow \\
\text { SOD } \downarrow \\
\text { MDA } \uparrow\end{array}$ & [74] \\
\hline
\end{tabular}


TABle 1: Continued.

\begin{tabular}{|c|c|c|c|c|c|c|c|}
\hline & Strain & Gender & D-gal doses & $\begin{array}{l}\text { Period of } \\
\text { exposure }\end{array}$ & Age & Aging effects & Ref. \\
\hline & & & & & & $\begin{array}{c}\text { CAT } \uparrow \text { and GSH-Px } \uparrow \\
\text { p16 } \uparrow \text { and p } 21 \uparrow \\
\text { Sirtuin } 1 \downarrow \text { and cyclin D1 } \downarrow\end{array}$ & \\
\hline 12 & $\begin{array}{l}\text { Kunming } \\
\text { mice }\end{array}$ & Male & $\begin{array}{l}200 \mathrm{mg} / \mathrm{kg} \text { daily } \\
\text { intraperitoneally }\end{array}$ & 30 days & Unknown & HYP $\downarrow$ & [75] \\
\hline & & & & & & $\begin{array}{c}\text { Skin elasticity } \downarrow \\
\text { Dermal thickness } \downarrow\end{array}$ & \\
\hline 13 & Nude mice & $\begin{array}{l}\text { Not } \\
\text { reported }\end{array}$ & $\begin{array}{c}1000 \mathrm{mg} / \mathrm{kg} \text { daily } \\
\text { subcutaneous injection }\end{array}$ & 8 weeks & 6 weeks & $\begin{array}{l}\mathrm{SOD} \downarrow \\
\mathrm{MDA} \uparrow \\
\mathrm{AGEs} \uparrow\end{array}$ & [76] \\
\hline 14 & Nude mice & Male & $\begin{array}{c}1000 \mathrm{mg} / \mathrm{kg} \text { daily } \\
\text { subcutaneous injection }\end{array}$ & 3 weeks & 6 weeks & $\begin{array}{l}\text { CD31 expression } \downarrow \text {. } \\
\text { Collagen } \downarrow \\
\text { Dermal thickness } \downarrow\end{array}$ & [77] \\
\hline 15 & Nude mice & $\begin{array}{l}\text { Not } \\
\text { reported }\end{array}$ & $\begin{array}{l}1000 \mathrm{mg} / \mathrm{kg} \text { daily } \\
\text { subcutaneous injection }\end{array}$ & 8 weeks & 6 weeks & $\begin{array}{c}\text { AGE } \uparrow \\
\text { SOD } \downarrow \\
\text { MDA } \uparrow \\
\text { Dermal thickness } \downarrow \\
\text { Collagen } \downarrow\end{array}$ & [78] \\
\hline 16 & $\mathrm{BALB} / \mathrm{c}$ & Male & $\begin{array}{l}500 \mathrm{mg} / \mathrm{kg} \text { daily per oral } \\
\text { administration }\end{array}$ & 6 weeks & 12 weeks & $\begin{array}{l}\text { Fibroblast count } \downarrow \\
\quad \text { Collagen } \downarrow\end{array}$ & [86] \\
\hline \multicolumn{8}{|c|}{ Rats } \\
\hline 17 & Wistar & Male & $\begin{array}{c}125 \mathrm{mg} / \mathrm{kg} \text { daily } \\
\text { subcutaneous injection }\end{array}$ & 6 weeks & Unknown & $\begin{array}{c}\text { Dermal thickness } \downarrow \\
\text { Skin moisture-no difference } \\
\text { HYP } \downarrow \\
\text { Collagen type I expression } \downarrow\end{array}$ & [79] \\
\hline 18 & Wistar & Female & $\begin{array}{l}150 \mathrm{mg} / \mathrm{kg} \text { daily } \\
\text { intraperitoneally }\end{array}$ & 12 weeks & $\begin{array}{c}170-180 \\
\text { days }\end{array}$ & $\begin{array}{l}\text { Skin moisture } \downarrow \\
\text { HYP } \downarrow\end{array}$ & [80] \\
\hline 19 & Wistar & Male & $\begin{array}{l}200 \mathrm{mg} / \mathrm{kg} \text { daily } \\
\text { intraperitoneally }\end{array}$ & 6 weeks & Unknown & $\begin{array}{l}\text { Rats had brittle and less elastic hair } \\
\text { Thin, inelastic, and sagged skin is reported }\end{array}$ & [85] \\
\hline 20 & $\begin{array}{l}\text { Sprague- } \\
\text { Dawley }\end{array}$ & Male & $\begin{array}{l}1000 \mathrm{mg} / \mathrm{kg} \text { daily } \\
\text { subcutaneous injection }\end{array}$ & 8 weeks & 4-6 weeks & Skin elasticity $\downarrow$ & [81] \\
\hline 21 & $\begin{array}{l}\text { Sprague- } \\
\text { Dawley }\end{array}$ & $\begin{array}{l}\text { Male and } \\
\text { female }\end{array}$ & $\begin{array}{l}100 \mathrm{mg} / \mathrm{kg} \text { daily } \\
\text { hypodermically injected }\end{array}$ & 8 weeks & Unknown & $\begin{array}{c}\text { CAT } \downarrow \text { and GSH-Px } \downarrow \\
\text { MDA } \uparrow \\
\text { Dermal thickness } \downarrow \text {. }\end{array}$ & [82] \\
\hline
\end{tabular}

HYP: skin hydroxyproline; SOD: skin superoxide dismutase; MDA: malondialdehyde; GSH-Px: glutathione peroxidase; CAT: catalase; GSH: glutathione Stransferase.

Dogs have also been used in tests for assessing D-galinduced toxicity [96-104]. The main focus of research on dogs has been focused to assess the effects of galactose on eye damage [97-104]. Several studies have revealed that a $30 \%$ galactose diet induces galactosemia and development of diabetes-like microvascular lesions of the retina [97-101, 103]. It has also been shown that a diet containing 30\% galactose rapidly accelerates cataract formation in galactose-fed dogs [102, 104]. Evidence shows that eye damage in galactose-fed dogs causes osmotic shock and is linked to aldose reductase [102]. There was only one study on a Dgal-induced aging model in dogs carried out by Ji and coauthors [96]. They demonstrated that D-gal, at $50 \mathrm{mg} / \mathrm{kg}$ daily subcutaneous injections for 90 days, increased the levels of MDA and suppression of SOD and GSH-Px in serum and brain tissue. It was reported that histopathological features were identified in the liver, kidney, heart, lung, spleen, and brain of galactose beagles. Moreover, a decreased expression level of proliferating cell nuclear antigen (PCNA) and enhanced expression levels of p16 and p21 were revealed in the $\mathrm{D}$-gal-induced aging group compared with the young control group [96]. In contrast to studies conducted on rodents, assessment of the skin condition in dogs with experimental galactosemia was not carried out.

Thus, based on the presented data, it is reasonable to conclude that $\mathrm{D}$-galactose induces skin aging in mammals. However, most of the studies were focused on the evaluation of antioxidant properties of new drugs or methods rather than exploring toxic effects of D-gal. To date, we know very little about effective dosages for skin aging induction since there is heterogeneity and inconsistency found in the above-cited publications. The proposed models have good experimental potential; yet, more studies are needed for the optimization of the laboratory animal skin aging models. The exact 
molecular mechanisms underlying D-gal-induced skin aging still remain unclear and require further investigations. In this regard, we discuss several pathways implicated in the D-galmediated skin cell senescence and cytotoxicity in the section that follows.

\section{Molecular Mechanisms of D-gal-Induced Skin Aging}

There is a growing body of evidence suggesting that D-gal is able to induce senescence of dermal fibroblasts in vitro [53]. For example, Elzi and coauthors showed that GALK1deficient fibroblasts had increased senescence, which was associated with the accumulation of intracellular D-gal [105]. D-gal administration (10 mM of D-gal for $48 \mathrm{~h}$ ) induced acceleration of senescence of GALK1-deficient fibroblasts while recovery of wild-type GALK1 expression led to the reversing of this process [105]. Another study showed that treatment of human dermal fibroblasts with $\mathrm{D}$-gal $(10 \mathrm{mg} / \mathrm{mL})$ for two days resulted in $50 \% \mathrm{SA}-\beta$-gal-positive staining of cells and this was linked to the reduction of cell growth and G0/G1 phase arrest [106]. The notion that Dgal is able to affect the cell cycle in human fibroblasts has also been confirmed by Cui et al. [107]. The authors reported that the proportion of the cells in the G0-G1 stage was increased while the levels of G2-M cells and cell growth rate were decreased in the fibroblasts treated with $8 \mathrm{~g} / \mathrm{L}$ of D-gal compared to the untreated cells. In addition, it has been established that D-gal affects genome integrity [108]. In this study, the incubation of porcine fibroblasts with D-gal ( $50 \mathrm{~g} / \mathrm{L})$ for 96 hours caused deformation of cell and chromatin shapes, induced chromatin condensation, and, in some cases, caused nuclear fragmentations and folds.

The most feasible mechanisms of D-gal-induced senescence are oxidative stress and suppression of the antioxidant system [109]. It has been demonstrated that the production of $\mathrm{H}_{2} \mathrm{O}_{2}$ significantly increased in mouse skin after D-gal treatment [84]. In turn, increased oxidative stress leads to lipid peroxidation, as evidenced by an increase in the concentration of MDA in the skin [72-74, 76, 78, 82-84]. In contrast, the activity of SOD was decreased in the skin after D-gal treatment $[70,73,76,78,83,84]$. Some contradictory results have been reported about the activity of other elements of the antioxidant system. For instance, biochemical analysis of the D-gal-treated skin showed that activities of CAT, GSH-Px, and GSH were reduced in some studies $[73,82-84]$. On the contrary, it was demonstrated that CAT [74] and GSH-Px activities were increased in D-galtreated animals $[72,74]$.

A recent study based on untargeted metabolomic approach with mass spectrometry and dual liquid chromatography tested 14 main pathways, including the multiple redox, amino acid, and mitochondrial pathways, to understand the pathophysiology of long-term outcomes in classic galactosemia [110]. The findings of the study indicated that cysteine, vitamins $\mathrm{E} / \mathrm{B}_{3}$, amino acid metabolism, and pathways involving mitochondria (e.g., carnitine shuttle, porphyrin metabolism, and nicotinate (niacin) metabolism) were impaired in plasma samples of the patients with classic galac- tosemia. Authors have suggested that galactosemia was associated with oxidative stress and/or perturbed redox signaling. It was also shown that at a pathologically high concentration (greater than $5.0 \mathrm{mM}$ ), D-gal increases lipid peroxidation, decreases total sulfhydryl content, and alters antioxidant defenses in rat plasma and erythrocytes [45]. Moreover, increased expression of biomarkers of the oxidative stress and decreased antioxidant defense were induced by D-gal in human fibroblasts in vitro $[111,112]$.

The important factors leading to oxidative stress are mitochondrial oxidative impairment and nicotinamide adenine dinucleotide phosphate oxidase (NADPH) oxidase activation resulting in overproduction of reactive oxygen species (ROS) [65, 113-116]. It was reported that D-gal reduced the efficiency of oxidative phosphorylation (OXPHOS) via declined transmembrane potential, decreasing ATP production and changing of respiratory function $[65,113,114]$. Upon galactose exposure, human fibroblasts tended to reduce the mitochondrial quantity and mitochondrial DNA (mtDNA) copy number and enhance mtDNA damage $[111,117,118]$.

D-gal-induced oxidative stress probably depends on several factors. One of them may be the accumulation of AGEs $[66,119]$. This is highlighted by a significant increase in AGE levels in the nude mouse skin treated by D-gal $(1000 \mathrm{mg} / \mathrm{kg})$ for 8 weeks [76]. In turn, AGEs can trigger cell damage through 3 main mechanisms: (1) accumulation of the AGEs in the extracellular matrix (ECM) (collagen and elastic fibers) initiates a crosslinking process between AGEs and ECM, which results in the reduction of connective tissue elasticity; (2) glycated modifications of intracellular proteins lead to an impaired cellular function; and (3) binding of AGEs to the receptor for AGE (RAGE) causes activation of inflammatory signaling pathways, NADPH oxidase activation, ROS generation, and apoptosis [120, 121]. Antibodies against RAGE and RAGE inhibitors were capable of inhibiting the generation of ROS from NADPH oxidase and suppressing the expression of proinflammatory cytokines in vitro $[122,123]$.

It has been reported that the ubiquitin-proteasome system (UPS) and autophagy are involved in the removal of AGEs [124]. However, the abovementioned factors themselves can have negative influence on the protein degradation systems in cells [125]. It was established that D-gal can disturb ubiquitin-proteasome system [125] and thus enhance the levels of glycated proteins in the cells. It should also be noted that autophagic flux alterations were detected recently in D-gal-treated skin fibroblasts $[111,117]$. This can provide an insight on the additional mechanism of the acceleration of D-gal-induced cell senescence.

Oxidative DNA damage induced by D-gal may be crucial for the development of skin aging. The role of both nuclear and mtDNA damage in skin cells induced by excessive ROS is well described in relation to the UV-induced skin aging process [9, 126]. Similar DNA damage was found in fibroblasts treated with D-gal [111, 117, 118]. It was established that oxidative DNA damage activates the downstream mitogen-activated protein kinases (MAPKs) including extracellular signal-regulated kinase (ERK), p38, and c-Jun NH2-terminal kinase (JNK) [127]. These kinases 
act as upstream activators of nuclear factor $-\kappa \mathrm{B}(\mathrm{NF}-\kappa \mathrm{B})$ and transcription factor activator protein-1 (AP-1). In their active states, both transcription factors function as repressors of collagen production and activators of matrix metalloproteinases (MMPs) in fibroblasts [128]. One of the MMP that is activated by NF- $\kappa$ B and AP- 1 is MMP- 1 . This metalloprotease is responsible for the primary step of collagen fiber fragmentation. Later on, two additional metalloproteases, MMP-3 and MMP-9, activated in response to the NF- $\kappa \mathrm{B}$ and AP-1, further degrade the collagen in the skin $[129,130]$. This was consistent with the data on the enhanced expression of NF- $\kappa \mathrm{B}$ and MMP-9 in fibroblasts treated by D-gal as reported by Voets et al. [112]. In addition, NF- $\kappa \mathrm{B}$ activation was detected in various tissues of dogs after exposure to D-gal [96].

In dermal fibroblasts, the AP-1 transcription factor (described above) also acts as a repressor of the transforming growth factor beta (TGF- $\beta$ ) signaling pathway. This pathway is one of the main activators of collagen expression and expression of other ECM proteins in the skin [131]. Therefore, the downregulation of the TGF- $\beta$ signaling pathway in response to ROS leads to the reduction of collagen expression and an increased rate of collagen degradation. In summary, activation of MMPs and repression TGF- $\beta$ signaling have a significant negative impact on collagen production and skin aging. Moreover, it was indicated that $\mathrm{D}$-gal reduced TGF- $\beta$-induced myofibroblast differentiation and collagen production [132].

ROS formation also induces low-grade inflammation, known as inflamm-aging, and is considered another critical factor of skin aging [133]. According to a recently proposed model, oxidative stress leads to accumulation of oxidized lipids and damaged epidermal cells. This triggers the complement system activation and inflammation, which in turn induces macrophage infiltration into the skin. Macrophages can release MMPs, but when overburdened with oxidized lipids and other toxic compounds, they tend to release ROS and proinflammatory cytokines [134]. In this context, it should be mentioned that the increased levels of expression of interleukin- (IL-) $1 \mathrm{~B}$ and tumor necrosis factor (TNF) in fibroblasts treated by Dgal were detected [112].

Dermis vasculature is yet another important component that plays a crucial role in the skin aging process. During this process, the number and the size of vascular vessels significantly reduce, aiding to overall vasculature reduction in the dermis [135]. This reduction is suggested to be a result of vascular endothelial growth factor (VEGF) signaling cascade impairment [136]. However, the molecular mechanisms describing the galactose effect on the VEGF signaling pathway during the skin aging process are yet to be determined. For instance, Chen and coauthors demonstrated that D-gal induces senescence of human umbilical vein endothelial cells (HUVECs) and represses angiogenesis and wound healing in vivo [83]. On the other hand, treatment by D-gal did not significantly change VEGF production in retinal cells in vitro [137]. Some information exists for the diabetic, hyperglycemic conditions. Hyperglycemia also induces the generation of ROS, which impairs wound healing [138]. Dur- ing wound healing, keratinocytes, fibroblasts, endothelial cells, macrophages, and platelets produce various growth factors and cytokines, one of which is VEGF [139]. Therefore, the impairment of VEGF may reduce the overall reepithelization process in the skin.

Taking together the information above, it is tempting to speculate that ROS produced via D-galactose accumulation may streamline through the same downstream effectors of ROS, such as transcription factors NF- $\kappa \mathrm{B}$ and AP-1, as well as the impairment of VEGF signaling, and hence further enhance the negative impact on collagen degradation and skin aging.

The possible role of galactose in the accumulation of metabolites in tissues, which can lead to cell damage, should also be taken into account. One of the possible underlying mechanisms of D-gal-induced senescence is osmotic shock caused by the accumulation of galactitol [63]. D-gal is usually metabolized by conversion to G1P via the Leloir pathway [88]. Intake of high doses of D-gal may also lead to galactitol accumulation via a reaction catalyzed by aldose reductase [66]. It was reported that human skin fibroblasts accumulated 20 times more galactitol than sorbitol when incubated in the presence of an unusually high concentration of galactose [140]. However, Kubo and colleagues suggested that the significance of osmotic shock for D-gal toxicity was exaggerated and this mechanism is based on free radical production [141]. They demonstrated that an abundance of galactitol leads to activation of aldose reductase, consequent exhaustion of the NADPH, and suppression of glutathione reductase activity. Also, it can promote changes in the oxidative status of the cells.

Furthermore, many studies demonstrated the possible key role of Gal-1-P in the development of toxic effects caused by an increased concentration of galactose in the blood [53]. Gal-1-P is the product of the first step of galactose metabolism, where galactose is converted into Gal-1-P by GALK1 [50]. In case of metabolic dysfunction or a very high level of galactose, it was established that Gal-1-P accumulates in different tissues [142], including skin fibroblasts [143] of galactosemic patients exposed to galactose. Recent studies have shown that the treatment of neonate skin fibroblast cultures with Gal-1-P significantly enhanced cellular levels of $\mathrm{NO}$ and inducible nitric oxide (iNOS) more than galactose treatment [144]. In addition, Gal-1-P downregulates expression of insulin-like growth factor 1 (IGF-1) [144]. Another study showed that elevated levels of Gal-1-P disrupt the phosphatidylinositol bisphosphate- (PI(P)2-) dependent signaling pathway in GALT-deficient tissues by restriction of the inositol phosphate turnover and reduction of the inositol level in tissues $[145,146]$. In this context, it should be noted that inositol has antioxidant properties and reduces oxidative stress [147].

In summary, galactose possesses a cytotoxic potential, and it is able to cause senescence of skin cells in vitro. The mechanisms underlying this process are not fully understood yet, but the most likely candidate for these mechanisms is the development of oxidative stress, which can also occur as an outcome of other toxic mechanisms. The main mechanisms of D-gal cytotoxicity are summarized in Figure 2. 


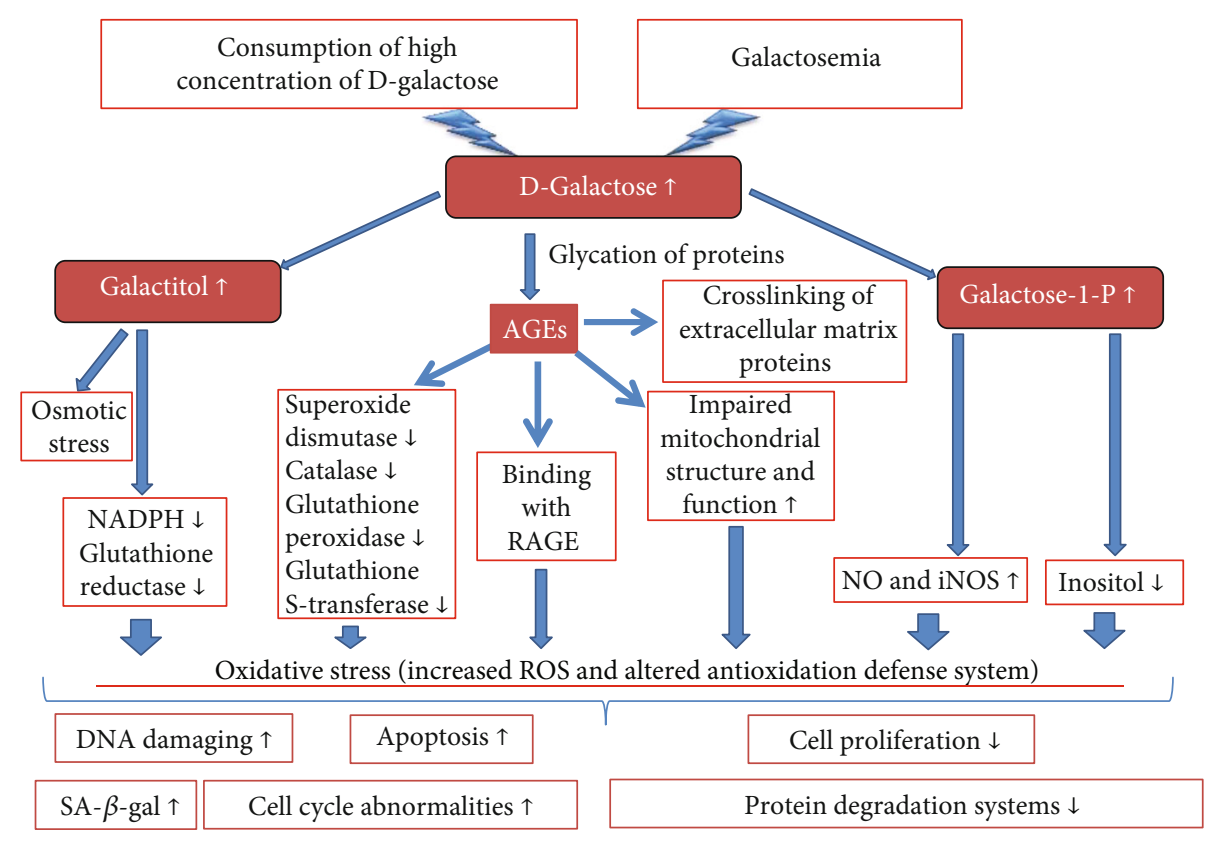

Figure 2: Schematic illustration of D-galactose cytotoxicity

\section{Natural Antioxidants and Polyphenols in Studies on D-gal-Induced Aging}

Aging models based on the administration of D-gal have been intensively utilized for validation of the antiaging efficacy of natural antioxidant compounds over the last decades [148]. In fact, the antioxidant properties of polyphenols have been tested in a number of studies using a model of skin aging based on the use of D-gal [149-152]. For instance, it was established that the combined treatment using resveratrol and calorie restriction restores hair condition, skin elasticity, and skin thickness in rats treated by D-gal [85]. In another study, apigenin (4,5,7-trihydroxyflavone), a flavone subclass of flavonoid, was able to significantly repair both collagen type I and type III density and thickness of the skin of D-gal-treated mice [67]. Ye and coworkers showed that extracts from Idesia polycarpa-defatted fruit residue containing phenolic and flavonoid components could improve the skin conditions of D-gal-treated mice (increase SOD activity; maintain collagen, elastin, and moisture content; and decrease MDA content) [70]. Tian et al. reported that persimmon-condensed tannin could dose-dependently reverse mouse skin aging induced by D-gal [71]. The same study established that another polyphenol, proanthocyanidin from grape seeds, possesses an antiaging activity for the skin but to a lesser extent than tannin [71].

Epigallocatechin gallate (EGCG), tea catechin, is one of the well-studied polyphenols up to date, with proven antiinflammatory, antioxidant, and antiaging properties [153156]. Chen and coworkers scrutinized the antiaging potential of EGCG on a D-gal-induced aging animal model [84]. The results showed that the conditions of the skin of EGCGtreated groups were improved such that the whole structure of the skin was better compared to the control. The levels of oxidative stress and the expression of EGFR proteins were significantly higher than those in the control group. These findings suggest that EGCG can effectively alter skin aging.

The antiaging effect of Inula britannica flower flavonoids on D-gal-induced aging mice was demonstrated by Chen et al. [74]. The results showed that Inula britannica could effectively improve the antioxidant enzyme activity of the aging mice, enhance the activities of SOD, CAT, and GSHPx of skin tissue, and decrease the MDA content. In addition, it was also revealed that these flavonoids can help maintain the skin collagen, HYP, dermal thickness, and moisture content. Moreover, Inula britannica was able to decrease the number of cells arrested in the G0/G1 phase and increase the expression of Sirt1 and cyclin D1 along with a decrease in the expression of $\mathrm{p} 16$ and $\mathrm{p} 21$. These results indicate that Inula britannica extracts can be used as a potential natural antiskin aging agent.

In another study, Sukoyan et al. evaluated the effect of $2 \%$ Cynara scolymus L. (extracts of artichoke plant) on inflammation in a D-gal-induced skin aging animal model [80]. The data of the study showed that Cynara scolymus L. extracts were able to restore skin relative weight and hexosamine/collagen (HYP) ratio along with decreasing the activity of NF- $\kappa \mathrm{B}$. Topical treatment also improved collagen metabolism and attenuated the progression of inflammation in a Dgal-induced skin aging model. In addition, Sulistyoningrum and coauthors demonstrated that dermal fibroblast count, density of dermal collagen, and plasma MDA were restored by Muntingia calabura aqueous leaf extract (MCALE) $(35 \mathrm{mg} / \mathrm{kg})$ and vitamin C $(28 \mathrm{mg} / \mathrm{kg})$ on a D-gal-induced mouse model of skin aging [86].

Apart from polyphenols, other natural antioxidant compounds have also been intensively studied with regard to their use for D-gal-induced aging research. Li and coauthors 
demonstrated that purified fractions of soluble polysaccharides derived from Agaricus bisporus $(400 \mathrm{mg} / \mathrm{kg}$ ) and vitamin C $(200 \mathrm{mg} / \mathrm{kg})$ had potential antiaging effects against D-gal-induced skin aging [69]. Moreover, Jing et al. showed that the acidic- and alkalic-extractable mycelium polysaccharides (extracted from Agrocybe aegerita) increased the amount of collagen in the skin in a D-gal-induced skin aging animal model [75].

Zheng et al. investigated antioxidant activities of marine pepsin-soluble collagen (PSC) derived from the skin of yellow goosefish (Lophius litulon) on oxidative stress in a Dgalactose-induced skin aging animal model. It was established that PSC could decelerate the progress of wrinkle development and skin elasticity reduction and inhibit oxidative stress induced by D-gal [73]. The antiaging activity of low molecular weight peptide (LMWP) extracted from Paphia undulate was demonstrated by Chen et al. [82]. The researchers established that LMWP was able to reduce oxidative stress and enhance thickness and elasticity of the skin in a D-gal-induced animal model.

In addition to natural compounds, synthetic molecules have also been explored for their antiaging properties. Intradermal microinjection of dimethylaminoethanol (DMAE), an analog of the $B$ vitamin choline and a precursor of acetylcholine, and compound amino acid (AA) caused an increase in dermal thickness, total collagen content, and collagen type I in D-gal-treated rats [79]. Another study demonstrated that argireline, a synthetic peptide, which is patterned from the $\mathrm{N}$-terminal end of SNAP-25 protein, possesses a significant antiwrinkle activity, and it can improve morphology of the skin. Moreover, it can inhibit oxidative processes induced by D-gal [68].

Alternatively, stem cell therapy has been also considered a treatment of aging-associated diseases. For example, Zhang et al. demonstrated that the transplantation of adiposederived stem cells (ADSCs) into the skin of D-gal-treated mice significantly improved skin elasticity and dermal thickness and accelerated angiogenesis [78]. Transplantation of ADSC reduced MDA and activated SOD activity, and it was associated with a decrease in mouse AGE levels postADSC treatment. Similar results were reported by Wang et al. [76]. In another study, $\mathrm{Li}$ and colleagues examined the combined treatment of adipose-derived stem cells (ADSCs) and fullerenol (as antioxidant) on skin aging induced by Dgal. It was found out that fullerenol suppressed the retention rate of transplanted ADSCs and enhanced dermal thickness and collagen ratio in mice [77]. Recently, Chen et al. investigated the effects of human embryonic stem cell-derived exosomes (ESC-Exos) on the aged mouse skin pressure ulcer model based on the administration of D-gal [83]. It was established that ESC-Exos promoted wound closure and increased angiogenesis. The senescence of vascular endothelial cells was significantly reduced after ESC-Exos exposure in D-gal-treated mice [83].

Taking the abovementioned into consideration, it could be concluded that natural compounds with antioxidant properties demonstrated significant potential in antiaging research, particularly for a D-gal-induced skin aging model.

\section{Conclusions}

This review discussed the evidence of D-gal-induced skin aging based on a range of in vitro and in vivo studies. It was shown that the toxic impact of galactose is manifested at high concentrations in the body [53]. However, to date, organspecific systemic toxicity studies that have been conducted, particularly with regard to the skin during galactosemia or increased consumption of galactose, do not reflect the full picture of galactose toxicity. Also, little is known about the exact underlying pathogenic mechanisms. It can be assumed that D-gal induces skin aging in two ways: the direct impact of D-gal on skin cells and/or the indirect effect associated with the accumulation of toxic metabolites in the skin. Our understanding at this age leads us to suggest that cytotoxicity of D-gal is based on activated oxidative stress, as confirmed by the in vitro $[65,111-118,144]$ and in vivo experiments [70, 72-74, 76, 78, 82-85].

Although a significant body of evidence suggests that high D-gal concentrations can induce skin aging, these are largely circumstantial $[66-80,82-86]$. To the best of our knowledge, skin aging has not been identified in patients with galactosemia $[87,157]$. On the other hand, abnormal glycosylation of collagen was detected in bones of galactosemic patients [94]. Based on this evidence, one should potentially expect to find abnormal glycosylated collagen in skin tissues in patients diagnosed with galactosemia. To address this point and validate our assumption, further research attempts are required along with the search for alternative underlying molecular mechanisms.

\section{Conflicts of Interest}

The authors declare that they have no competing interests related to this work.

\section{Acknowledgments}

The work was funded through the grant of the Ministry of Education and Science of the Republic of Kazakhstan (No. 0118PK01029).

\section{References}

[1] M. A. Farage, K. W. Miller, P. Elsner, and H. I. Maibach, "Intrinsic and extrinsic factors in skin ageing: a review," International Journal of Cosmetic Science, vol. 30, no. 2, pp. 87-95, 2008.

[2] M. A. Farage, K. W. Miller, and H. I. Maibach, "Determinants in the rate of skin aging: ethnicity, gender, and lifestyle influences," in Textbook of Aging Skin, M. A. Farage, K. W. Miller, and H. I. Maibach, Eds., pp. 1709-1727, Springer Berlin Heidelberg, Berlin, Heidelberg, 2017.

[3] D. A. Gunn, "The genetics of skin aging," in Textbook of Aging Skin, M. A. Farage, K. W. Miller, and H. I. Maibach, Eds., pp. 1-14, Springer Berlin Heidelberg, Berlin, Heidelberg, 2014.

[4] E. Makrantonaki, V. Bekou, and C. C. Zouboulis, "Genetics and skin aging," Dermato-endocrinology, vol. 4, pp. 280284, 2012. 
[5] A. C. Green, M. C. B. Hughes, P. McBride, and A. Fourtanier, "Factors associated with premature skin aging (photoaging) before the age of 55: a population-based study," Dermatology, vol. 222, no. 1, pp. 74-80, 2011.

[6] D. J. Tobin, "Introduction to skin aging," Journal of Tissue Viability, vol. 26, no. 1, pp. 37-46, 2017.

[7] D. McDaniel, P. Farris, and G. Valacchi, "Atmospheric skin aging-contributors and inhibitors," Journal of Cosmetic Dermatology, vol. 17, no. 2, pp. 124-137, 2018.

[8] A. J. Argyropoulos, P. Robichaud, R. M. Balimunkwe et al., "Alterations of dermal connective tissue collagen in diabetes: molecular basis of aged-appearing skin," PLoS One, vol. 11, no. 4, article e0153806, 2016.

[9] U. Panich, G. Sittithumcharee, N. Rathviboon, and S. Jirawatnotai, "Ultraviolet radiation-induced skin aging: the role of DNA damage and oxidative stress in epidermal stem cell damage mediated skin aging," Stem Cells International, vol. 2016, Article ID 7370642, 14 pages, 2016.

[10] M. Wlaschek, I. Tantcheva-Poór, L. Naderi et al., "Solar UV irradiation and dermal photoaging," Journal of Photochemistry and Photobiology B: Biology, vol. 63, no. 1-3, pp. 41-51, 2001.

[11] G. D. Goodman, J. Kaufman, D. Day et al., "Impact of smoking and alcohol use on facial aging in women: results of a large multinational, multiracial, cross-sectional survey," The Journal of Clinical and Aesthetic Dermatology, vol. 12, no. 8, pp. 28-39, 2019.

[12] S. K. Schagen, V. A. Zampeli, E. Makrantonaki, and C. C. Zouboulis, "Discovering the link between nutrition and skin aging," Dermato-endocrinology, vol. 4, no. 3, pp. 298-307, 2014.

[13] K. L. Stanhope, "Sugar consumption, metabolic disease and obesity: the state of the controversy," Critical Reviews in Clinical Laboratory Sciences, vol. 53, no. 1, pp. 52-67, 2015.

[14] K. J. Duffey and B. M. Popkin, "High-fructose corn syrup: is this what's for dinner?," The American Journal of Clinical Nutrition, vol. 88, no. 6, pp. 1722S-1732S, 2008.

[15] R. Botchlett, S.-L. Woo, M. Liu et al., "Nutritional approaches for managing obesity-associated metabolic diseases," The Journal of Endocrinology, vol. 233, no. 3, pp. R145-R171, 2017.

[16] E. C. Stefanadi, G. Dimitrakakis, C.-K. Antoniou et al., "Metabolic syndrome and the skin: a more than superficial association. Reviewing the association between skin diseases and metabolic syndrome and a clinical decision algorithm for high risk patients," Diabetology \& Metabolic Syndrome, vol. 10, no. 1, pp. 9-9, 2018.

[17] A. Ness, "Diet, Nutrition and the Prevention of Chronic Diseases. WHO Technical Report Series 916. Report of a Joint WHO/FSA Expert Consultation," International Journal of Epidemiology, vol. 33, no. 4, pp. 914-915, 2004.

[18] R. Katta and M. J. Kramer, "Skin and diet: an update on the role of dietary change as a treatment strategy for skin disease," Skin Therapy Letter, vol. 23, no. 1, pp. 1-5, 2018.

[19] N. Lakdawala, O. Babalola III, F. Fedeles et al., "The role of nutrition in dermatologic diseases: facts and controversies," Clinics in Dermatology, vol. 31, no. 6, pp. 677-700, 2013.

[20] M. C. Cosgrove, O. H. Franco, S. P. Granger, P. G. Murray, and A. E. Mayes, "Dietary nutrient intakes and skin-aging appearance among middle-aged American women," The
American Journal of Clinical Nutrition, vol. 86, no. 4, pp. 1225-1231, 2007.

[21] H. Nguyen and R. Katta, "Sugar sag: glycation and the role of diet in aging skin," Skin Therapy Letter, vol. 20, no. 6, pp. 1-5, 2015.

[22] F. W. Danby, "Nutrition and aging skin: sugar and glycation," Clinics in Dermatology, vol. 28, no. 4, pp. 409-411, 2010.

[23] R. G. Paul and A. J. Bailey, "Glycation of collagen: the basis of its central role in the late complications of ageing and diabetes," The International Journal of Biochemistry \& Cell Biology, vol. 28, no. 12, pp. 1297-1310, 1996.

[24] C. Jeanmaire, L. Danoux, and G. Pauly, "Glycation during human dermal intrinsic and actinic ageing: an in vivo and in vitro model study," British Journal of Dermatology, vol. 145, no. 1, pp. 10-18, 2001.

[25] H. Pageon, H. Zucchi, P. Pennacchi, and D. Asselineau, Glycation and Skin Aging, 2017.

[26] N. C. Avery and A. J. Bailey, "The effects of the Maillard reaction on the physical properties and cell interactions of collagen," Pathologie Biologie, vol. 54, no. 7, pp. 387-395, 2006.

[27] C. H. Kim, "Expression of extracellular superoxide dismutase protein in diabetes," Archives of Plastic Surgery, vol. 40, no. 5, pp. 517-521, 2013.

[28] G. N. Shah, Y. Morofuji, W. A. Banks, and T. O. Price, "High glucose-induced mitochondrial respiration and reactive oxygen species in mouse cerebral pericytes is reversed by pharmacological inhibition of mitochondrial carbonic anhydrases: implications for cerebral microvascular disease in diabetes," Biochemical and Biophysical Research Communications, vol. 440, no. 2, pp. 354-358, 2013.

[29] X. L. Du, D. Edelstein, L. Rossetti et al., "Hyperglycemiainduced mitochondrial superoxide overproduction activates the hexosamine pathway and induces plasminogen activator inhibitor-1 expression by increasing Sp1 glycosylation," Proceedings of the National Academy of Sciences of the United States of America, vol. 97, no. 22, pp. 1222212226, 2000.

[30] T. Nishikawa, D. Edelstein, X. L. du et al., "Normalizing mitochondrial superoxide production blocks three pathways of hyperglycaemic damage," Nature, vol. 404, no. 6779, pp. 787-790, 2000.

[31] D. Bonnefont-Rousselot, "Glucose and reactive oxygen species," Current Opinion in Clinical Nutrition \& Metabolic Care, vol. 5, no. 5, pp. 561-568, 2002.

[32] C. M. O. Volpe, P. H. Villar-Delfino, P. M. F. dos Anjos, and J. A. Nogueira-Machado, "Cellular death, reactive oxygen species (ROS) and diabetic complications," Cell Death \& Disease, vol. 9, no. 2, p. 119, 2018.

[33] N. Evcimen, N. Ulusu, C. Karasu, and B. Doğru, "Adenosine triphosphatase activity of streptozotocin-induced diabetic rat brain microsomes. Effect of vitamin E," General Physiology and Biophysics, vol. 23, no. 3, pp. 347-355, 2004.

[34] Y. Du, C. M. Miller, and T. S. Kern, "Hyperglycemia increases mitochondrial superoxide in retina and retinal cells," Free Radical Biology and Medicine, vol. 35, no. 11, pp. 14911499, 2003.

[35] H. P. Hammes, S. Martin, K. Federlin, K. Geisen, and M. Brownlee, "Aminoguanidine treatment inhibits the development of experimental diabetic retinopathy," Proceedings of the National Academy of Sciences of the United States of America, vol. 88, no. 24, pp. 11555-11558, 1991. 
[36] S. Nakamura, Z. Makita, S. Ishikawa et al., "Progression of nephropathy in spontaneous diabetic rats is prevented by OPB-9195, a novel inhibitor of advanced glycation," Diabetes, vol. 46, no. 5, pp. 895-899, 1997.

[37] E. R. Stadtman and R. L. Levine, "Protein oxidation," Annals of the New York Academy of Sciences, vol. 899, pp. 191-208, 2000.

[38] D. Koya and G. L. King, "Protein kinase C Activation and the development of diabetic complications," Diabetes, vol. 47, no. 6, pp. 859-866, 1998.

[39] E. Schleicher and C. Weigert, "Role of the hexosamine biosynthetic pathway in diabetic nephropathy," Kidney International Supplement, vol. 77, pp. S13-S18, 2000.

[40] A. G. Nerlich, U. Sauer, V. Kolm-Litty, E. Wagner, M. Koch, and E. D. Schleicher, "Expression of glutamine:fructose-6phosphate amidotransferase in human tissues: evidence for high variability and distinct regulation in diabetes," Diabetes, vol. 47 , no. 2, pp. 170-178, 1998.

[41] L. D. Gaspers, A. P. Thomas, V. Douard, and R. . P. Ferraris, "Mechanisms underlying fructose-induced oxidative stress in the cytosol and mitochondria," Biophysical Journal, vol. 98, no. 3, article 377a, 2010.

[42] R. Noordam, D. A. Gunn, C. C. Tomlin et al., "High serum glucose levels are associated with a higher perceived age," Age, vol. 35, no. 1, pp. 189-195, 2013.

[43] J. P. Dworkin and S. L. Miller, "A kinetic estimate of the free aldehyde content of aldoses," Carbohydrate Research, vol. 329, no. 2, pp. 359-365, 2000.

[44] H. F. Bunn and P. J. Higgins, "Reaction of monosaccharides with proteins: possible evolutionary significance," Science, vol. 213, no. 4504, pp. 222-224, 1981.

[45] D. Delwing-de Lima, S. B. Hennrich, D. Delwing-Dal Magro et al., "The effect of d-galactose induced oxidative stress on in vitro redox homeostasis in rat plasma and erythrocytes," Biomedicine \& Pharmacotherapy, vol. 86, pp. 686-693, 2017.

[46] J. Budni, R. Pacheco, S. da Silva et al., "Oral administration of $\mathrm{d}$-galactose induces cognitive impairments and oxidative damage in rats," Behavioural Brain Research, vol. 302, pp. 35-43, 2016.

[47] P. B. Acosta and K. C. Gross, "Hidden sources of galactose in the environment," European Journal of Pediatrics, vol. 154, no. S2, pp. S87-S92, 1995.

[48] C. A. Williams, "Galactose," in Encyclopedia of Food Sciences and Nutrition, B. Caballero, Ed., pp. 2843-2846, Academic Press, Oxford, UK, Second edition, 2003.

[49] K. C. Gross and P. B. Acosta, "Fruits and vegetables are a source of galactose: implications in planning the diets of patients with galactosaemia," Journal of Inherited Metabolic Disease, vol. 14, no. 2, pp. 253-258, 1991.

[50] A. I. Coelho, G. T. Berry, and M. E. Rubio-Gozalbo, "Galactose metabolism and health," Current Opinion in Clinical Nutrition and Metabolic Care, vol. 18, no. 4, pp. 422-427, 2015.

[51] G. T. Berry, I. Nissim, Z. Lin, A. T. Mazur, J. B. Gibson, and S. Segal, "Endogenous synthesis of galactose in normal men and patients with hereditary galactosaemia," The Lancet, vol. 346, no. 8982, pp. 1073-1074, 1995.

[52] G. T. Berry, I. Nissim, A. T. Mazur, and S. S. Segal, “The rate of endogenous galactose synthesis in normals and patients with galactose-1-phosphate uridyltransferase deficiency 704," Pediatric Research, vol. 43, pp. 122-122, 1998.
[53] K. Lai, L. J. Elsas, and K. J. Wierenga, "Galactose toxicity in animals,” IUBMB Life, vol. 61, no. 11, pp. 1063-1074, 2009.

[54] J. J. Zhang, X. Liu, J. H. Pan et al., "Anti-aging effect of brown black wolfberry on Drosophila melanogaster and Dgalactose-induced aging mice," Journal of Functional Foods, vol. 65, article 103724, 2020.

[55] K. F. Azman and R. Zakaria, "D-Galactose-induced accelerated aging model: an overview," Biogerontology, vol. 20, no. 6, pp. 763-782, 2019.

[56] J. G. Hou, Y. Yun, J. J. Xue, M. Q. Sun, and S. Kim, “D-Galactose induces astrocytic aging and contributes to astrocytoma progression and chemoresistance via cellular senescence," Molecular Medicine Reports, vol. 20, no. 5, pp. 4111-4118, 2019.

[57] W. Wasityastuti, N. A. Habib, D. C. R. Sari, and N. Arfian, "Effects of low and moderate treadmill exercise on liver of d-galactose-exposed aging rat model," Physiological Reports, vol. 7, no. 21, article e14279, 2019.

[58] Y. Z. Zhu and H. G. Zhu, "Establishment and measurement of D-galactose induced aging model," Fudan University Journal of Medical Sciences, vol. 34, pp. 617-619, 2007.

[59] V. B. Rahimi, V. R. Askari, and S. H. Mousavi, "Ellagic acid dose and time-dependently abrogates d-galactose-induced animal model of aging: Investigating the role of PPAR- $\gamma$," Life Sciences, vol. 232, article 116595, 2019.

[60] J. Budni, M. L. Garcez, M. L. Garcez et al., "Evaluation of folic acid protective effect in an animal model of aging induced by D-galactose," Biological Psychiatry, vol. 79, pp. 76s-76s, 2016.

[61] S. Sadigh-Eteghad, A. Majdi, S. K. McCann, J. Mahmoudi, M. S. Vafaee, and M. R. Macleod, "D-galactose-induced brain ageing model: a systematic review and meta-analysis on cognitive outcomes and oxidative stress indices," PLoS One, H. Ariga, Ed., vol. 12, no. 8, article e0184122, 2017.

[62] T. Shwe, W. Pratchayasakul, N. Chattipakorn, and S. C. Chattipakorn, "Role of D-galactose-induced brain aging and its potential used for therapeutic interventions," Experimental Gerontology, vol. 101, pp. 13-36, 2018.

[63] C. Bo-Htay, S. Palee, N. Apaijai, S. C. Chattipakorn, and N. Chattipakorn, "Effects of d-galactose-induced ageing on the heart and its potential interventions," Journal of Cellular and Molecular Medicine, vol. 22, no. 3, pp. 1392-1410, 2018.

[64] D. O. Saleh, D. F. Mansour, I. M. Hashad, and R. M. Bakeer, "Effects of sulforaphane on D-galactose-induced liver aging in rats: Role of keap-1/nrf-2 pathway.," European Journal of Pharmacology, vol. 855, pp. 40-49, 2019.

[65] S. Aydın, K. Yanar, P. Atukeren et al., "Comparison of oxidative stress biomarkers in renal tissues of d-galactose induced, naturally aged and young rats," Biogerontology, vol. 13, no. 3, pp. 251-260, 2012.

[66] X. Song, M. Bao, D. Li, and Y. M. Li, "Advanced glycation in D-galactose induced mouse aging model," Mechanisms of Ageing and Development, vol. 108, no. 3, pp. 239-251, 1999.

[67] Y. Zhang, J. Wang, X. Cheng, B. Yi, X. Zhang, and Q. Li, "Apigenin induces dermal collagen synthesis via smad $2 / 3$ signaling pathway," European Journal of Histochemistry, vol. 59, no. 2, pp. 98-106, 2015.

[68] Y. Wang, M. Wang, X. S. Xiao, J. Huo, and W. D. Zhang, "The anti-wrinkle efficacy of Argireline," Journal of Cosmetic and Laser Therapy, vol. 15, no. 4, pp. 237-241, 2013.

[69] S. Li, M. Liu, C. Zhang et al., "Purification, in vitro antioxidant and in vivo anti-aging activities of soluble 
polysaccharides by enzyme-assisted extraction from Agaricus bisporus," International Journal of Biological Macromolecules, vol. 109, pp. 457-466, 2018.

[70] Y. Ye, R.-r. Jia, L. Tang, and F. Chen, "In Vivo Antioxidant and Anti-Skin-Aging Activities of Ethyl Acetate Extraction from Idesia polycarpa Defatted Fruit Residue in Aging Mice Induced by D-Galactose," Evidence-Based Complementary and Alternative Medicine, vol. 2014, Article ID 185716, 12 pages, 2014.

[71] Y. Tian, B. Zou, L. Yang et al., "High molecular weight persimmon tannin ameliorates cognition deficits and attenuates oxidative damage in senescent mice induced by d-galactose," Food and Chemical Toxicology, vol. 49, no. 8, pp. 1728-1736, 2011.

[72] C. Yang, B. Xu, and Y. Sun, "Effects of acupuncture and moxibustion on MDA, GSH-Px, and hyp in the skin of senile mice," Journal of Acupuncture and Tuina Science, vol. 9, no. 3, pp. 142-144, 2011.

[73] B. Zheng, X. Xiang, Y. Zhou et al., "Characterization and antioxidant activities of marine pepsin soluble collagen from the skin of yellow goosefish Lophius litulon," Chinese Journal of Oceanology and Limnology, vol. 35, no. 3, pp. 634-644, 2017.

[74] H. Chen, Y. Long, and L. Guo, "Antiaging effect of Inula britannica on aging mouse model induced by D-galactose," Evidence-based Complementary and Alternative Medicine, vol. 2016, Article ID 6049083, 8 pages, 2016.

[75] H. Jing, J. Li, J. Zhang et al., “The antioxidative and anti-aging effects of acidic- and alkalic-extractable mycelium polysaccharides by _Agrocybe aegerita_ (Brig.) Sing," International Journal of Biological Macromolecules, vol. 106, pp. 12701278, 2018.

[76] H. Wang, S. Wei, X. Xue, Y. You, and Q. Ma, “Adipose stem cells' antagonism in glycosylation of $\mathrm{D}$-galactose-induced skin aging of nude mice and its skin recovery function," International Journal of Immunopathology and Pharmacology, vol. 29, no. 3, pp. 376-385, 2016.

[77] H. Jing, J. Li, J. Zhang et al., "Anti-aging effect of fullerenol on skin aging through derived stem cells in a mouse model," Experimental and Therapeutic Medicine, vol. 14, pp. 50455050, 2017.

[78] S. Zhang, Z. Dong, Z. Peng, and F. Lu, "Anti-aging effect of adipose-derived stem cells in a mouse model of skin aging induced by D-galactose," PLoS ONE, vol. 9, no. 5, 2014.

[79] S. Liu, Z. Chen, X. Cai et al., "Effects of dimethylaminoethanol and compound amino acid on D-galactose induced skin aging model of rat," The Scientific World Journal, vol. 2014, Article ID 507351, 7 pages, 2014.

[80] G. Sukoyan, E. Tsivtsivadze, V. Golovach, T. Kezeli, and N. Demina, "Anti-Aging Effect of Cynara cardunculus L. var. Cynara scolymus L. Extract in D-Galactose-Induced Skin Aging Model in Rats," Pharmacology \& Pharmacy, vol. 9, no. 10, pp. 428-439, 2018.

[81] Z. Liu, G. D. Hu, X. B. Luo et al., "Potential of bone marrow mesenchymal stem cells in rejuvenation of the aged skin of rats," Biomedical Reports, vol. 6, no. 3, pp. 279-284, 2017.

[82] X. Chen, B. Cai, H. Chen, J. Pan, D. Chen, and H. Sun, “Antiaging activity of low molecular weight peptide from Paphia undulate," Chinese Journal of Oceanology and Limnology, vol. 31, no. 3, pp. 570-580, 2013.

[83] B. Chen, Y. Sun, J. Zhang et al., "Human embryonic stem cellderived exosomes promote pressure ulcer healing in aged mice by rejuvenating senescent endothelial cells," Stem Cell Research \& Therapy, vol. 10, no. 1, 2019.

[84] J. Chen, Y. Li, Q. Zhu et al., “Anti-skin-aging effect of epigallocatechin gallate by regulating epidermal growth factor receptor pathway on aging mouse model induced by d-galactose," Mechanisms of Ageing and Development, vol. 164, pp. 1-7, 2017.

[85] J. Li, C. X. Zhang, Y. M. Liu, K. L. Chen, and G. Chen, “A comparative study of anti-aging properties and mechanism: resveratrol and caloric restriction," Oncotarget, vol. 8, no. 39, pp. 65717-65729, 2017.

[86] E. Sulistyoningrum, R. Rosmelia, M. K. Hamid, and W. S. T. Nuraini, "Anti-aging effects of Muntingia calabura leaves extract in D-galactose-induced skin aging mouse model," Journal of Applied Pharmaceutical Science, vol. 9, pp. 23-29, 2019.

[87] A. I. Coelho, M. E. Rubio-Gozalbo, J. B. Vicente, and I. Rivera, "Sweet and sour: an update on classic galactosemia," Journal of Inherited Metabolic Disease, vol. 40, no. 3, pp. 325342, 2017.

[88] H. M. Holden, I. Rayment, and J. B. Thoden, "Structure and function of enzymes of the Leloir pathway for galactose metabolism," Journal of Biological Chemistry, vol. 278, no. 45, pp. 43885-43888, 2003.

[89] D. D. Waggoner, N. R. M. Buist, and G. N. Donnell, "Longterm prognosis in galactosaemia: results of a survey of 350 cases," Journal of Inherited Metabolic Disease, vol. 13, no. 6, pp. 802-818, 1990.

[90] D. Demirbas, A. I. Coelho, M. E. Rubio-Gozalbo, and G. T. Berry, "Hereditary galactosemia," Metabolism, vol. 83, pp. 188-196, 2018.

[91] J. B. Hennermann, P. Schadewaldt, B. Vetter, Y. S. Shin, E. Mönch, and J. Klein, "Features and outcome of galactokinase deficiency in children diagnosed by newborn screening," Journal of Inherited Metabolic Disease, vol. 34, no. 2, pp. 399407, 2011.

[92] A. E. Carney, R. D. Sanders, K. R. Garza et al., "Origins, distribution and expression of the Duarte-2 (D2) allele of galactose-1-phosphate uridylyltransferase," Human Molecular Genetics, vol. 18, no. 9, pp. 1624-1632, 2009.

[93] M. Suzuki, C. West, and E. Beutler, "Large-scale molecular screening for galactosemia alleles in a pan-ethnic population," Human Genetics, vol. 109, no. 2, pp. 210-215, 2001.

[94] F. R. Kaufman, M. L. Loro, C. Azen, E. Wenz, and V. Gilsanz, "Effect of hypogonadism and deficient calcium intake on bone density in patients with galactosemia," The Journal of Pediatrics, vol. 123, no. 3, pp. 365-370, 1993.

[95] A. S. Wang and O. Dreesen, "Biomarkers of cellular senescence and skin aging," Frontiers in Genetics, vol. 9, p. 247, 2018.

[96] M. Ji, X. Su, J. Liu et al., "Comparison of naturally aging and D-galactose induced aging model in beagle dogs," Experimental and Therapeutic Medicine, vol. 14, 2017.

[97] P. F. Kador, Y. Takahashi, Y. Akagi et al., "Effect of galactose diet removal on the progression of retinal vessel changes in galactose-fed dogs," Investigative Ophthalmology \& Visual Science, vol. 43, no. 6, pp. 1916-1921, 2002.

[98] N. Ohta, J.-Y. Tsai, E. F. Secchi, P. F. Kador, and S. Sato, "Neutrophils in galactose-fed dogs: suppressed apoptosis and increased adhesion to retinal capillary endothelial cells," 
Journal of Diabetes and its Complications, vol. 13, no. 3, pp. 151-158, 1999.

[99] M. Murata, N. Ohta, S. Fujisawa et al., "Selective pericyte degeneration in the retinal capillaries of galactose-fed dogs results from apoptosis linked to aldose reductase-catalyzed galactitol accumulation," Journal of Diabetes and its Complications, vol. 16, no. 5, pp. 363-370, 2002.

[100] P. F. Kador, Y. Akagi, Y. Takahashi, H. Ikebe, M. Wyman, and J. H. Kinoshita, "Prevention of retinal vessel changes associated with diabetic retinopathy in galactose-fed dogs by aldose reductase inhibitors," Archives of Ophthalmology, vol. 108, no. 9, pp. 1301-1309, 1990.

[101] R. L. Engerman and T. S. Kern, "Experimental galactosemia produces diabetic-like retinopathy," Diabetes, vol. 33, no. 1, pp. 97-100, 1984.

[102] S. Sato, K. Mori, M. Wyman, and P. F. Kador, "Dose-dependent prevention of sugar cataracts in galactose-fed dogs by the aldose reductase inhibitor M79175," Experimental Eye Research, vol. 66, no. 2, pp. 217-222, 1998.

[103] M. Cusick, E. Y. Chew, F. Ferris III, T. A. Cox, C.-C. Chan, and P. F. Kador, "Effects of aldose reductase inhibitors and galactose withdrawal on fluorescein angiographic lesions in galactose-fed dogs," Archives of Ophthalmology, vol. 121, no. 12, pp. 1745-1751, 2003.

[104] P. A. Lackner, L. Rodriguez, S. Sato, M. J. Lizak, M. Wyman, and P. F. Kador, "Age-dependent lens changes in galactosefed dogs," Experimental Eye Research, vol. 64, no. 3, pp. 431-436, 1997.

[105] D. J. Elzi, M. Song, and Y. Shiio, "Role of galactose in cellular senescence," Experimental Gerontology, vol. 73, pp. 1-4, 2016.

[106] C. Meng, S. Wu, and D. Xing, "Efficacy of low-power laser irradiation in the prevention of D-galactose induced senescence in human dermal fibroblasts," Conference Mechanisms for Low-Light Therapy VI, the Moscone Center, in Progress in Biomedical Optics and Imaging - Proceedings of SPIE, vol. 7887, p. 15, San Francisco, California, United States, February 2011.

[107] X. Cui, W. Li, and B. Zhang, "Studies on cell senescence induced by D-galactose in cultured neurons and fibroblasts," Zhongguo ying yong sheng li xue za zhi = Zhongguo yingyong shenglixue zazhi = Chinese journal of applied physiology, vol. 13, no. 2, pp. 131-133, 1997.

[108] X. Xie, H. Zhang, P. Gao et al., "Overexpression of SIRT6 in porcine fetal fibroblasts attenuates cytotoxicity and premature senescence caused by D-galactose and tert-butylhydroperoxide," DNA and Cell Biology, vol. 31, pp. 745-752, 2012.

[109] S.-C. Ho, J.-H. Liu, and R.-Y. Wu, "Establishment of the mimetic aging effect in mice caused by D-galactose," Biogerontology, vol. 4, no. 1, pp. 15-18, 2003.

[110] S. Taylor Fischer, A. B. Frederick, V. Tran, S. Li, D. P. Jones, and J. L. Fridovich-Keil, "Metabolic perturbations in classic galactosemia beyond the Leloir pathway: insights from an untargeted metabolomic study," Journal of Inherited Metabolic Disease, vol. 42, no. 2, pp. 254-263, 2019.

[111] W. Ye, J.-M. Cao, X.-J. Tang et al., "Mitochondrial impairment mechanism in D-galactose-induced senescence in experimental fibroblast cell model," in Proceedings of the 2016 International Conference on Biological Sciences and Technology, January 2016.
[112] A. M. Voets, P. J. Lindsey, S. J. Vanherle et al., "Patientderived fibroblasts indicate oxidative stress status and may justify antioxidant therapy in OXPHOS disorders," Biochimica et Biophysica Acta (BBA) - Bioenergetics, vol. 1817, no. 11, pp. 1971-1978, 2012.

[113] Z. Du, Q. Yang, T. Zhou et al., "D-galactose-induced mitochondrial DNA oxidative damage in the auditory cortex of rats," Molecular Medicine Reports, vol. 10, no. 6, pp. 28612867, 2014.

[114] Z. Du, Y. Hu, Y. Yang et al., "NADPH oxidase-dependent oxidative stress and mitochondrial damage in hippocampus of D-galactose-induced aging rats," Journal of Huazhong University of Science and Technology [Medical Sciences], vol. 32, no. 4, pp. 466-472, 2012.

[115] L. Chang, X. Liu, J. Liu et al., "D-galactose induces a mitochondrial complex I deficiency in mouse skeletal muscle: potential benefits of nutrient combination in ameliorating muscle impairment," Journal of Medicinal Food, vol. 17, no. 3, pp. 357-364, 2014.

[116] J. Long, X. Wang, H. Gao et al., "d-Galactose toxicity in mice is associated with mitochondrial dysfunction: protecting effects of mitochondrial nutrient R-alpha-lipoic acid," Biogerontology, vol. 8, no. 3, pp. 373-381, 2007.

[117] I. González-Casacuberta, D.-L. Juárez-Flores, M. Ezquerra et al., "Mitochondrial and autophagic alterations in skin fibroblasts from Parkinson disease patients with Parkin mutations," Aging, vol. 11, no. 11, pp. 3750-3767, 2019.

[118] D. L. Juárez-Flores, I. González-Casacuberta, M. Ezquerra et al., "Exhaustion of mitochondrial and autophagic reserve may contribute to the development of LRRK2 (G2019S) -Parkinson's disease," Journal of Translational Medicine, vol. 16, no. 1, pp. 160-160, 2018.

[119] G.-X. Mao, L.-D. Zheng, Y.-B. Cao et al., “Antiaging effect of pine pollen in human diploid fibroblasts and in a mouse model induced by D-galactose," Oxidative Medicine and Cellular Longevity, vol. 2012, Article ID 750963, 10 pages, 2012.

[120] C.-S. Kim, S. Park, and J. Kim, "The role of glycation in the pathogenesis of aging and its prevention through herbal products and physical exercise," Journal of Exercise Nutrition \& Biochemistry, vol. 21, no. 3, pp. 55-61, 2017.

[121] M. P. Wautier, O. Chappey, S. Corda, D. M. Stern, A. M. Schmidt, and J. L. Wautier, "Activation of NADPH oxidase by AGE links oxidant stress to altered gene expression via RAGE," American Journal of Physiology-Endocrinology and Metabolism, vol. 280, no. 5, pp. E685-E694, 2001.

[122] S. Askarova, A. Tsoy, and J. C.-M. Lee, "RAGE targeted strategies for Alzheimer's amyloid $\beta$ peptide induced blood brain barrier dysfunctions," Molecular Neurodegeneration, vol. 8, no. S1, pp. P5-P5, 2013.

[123] G. Li, J. Tang, Y. Du, C. A. Lee, and T. S. Kern, "Beneficial effects of a novel RAGE inhibitor on early diabetic retinopathy and tactile allodynia," Molecular Vision, vol. 17, pp. 3156-3165, 2011.

[124] S. Rowan, E. Bejarano, and A. Taylor, "Mechanistic targeting of advanced glycation end-products in age-related diseases," Biochimica et Biophysica Acta (BBA) - Molecular Basis of Disease, vol. 1864, no. 12, pp. 3631-3643, 2018.

[125] Y. Zhang, X. Huang, X. Zhao, Y. Hu, H. Sun, and W. Kong, "Role of the ubiquitin C-terminal hydrolase L1-modulated ubiquitin proteasome system in auditory cortex senescence," ORL, vol. 79, no. 3, pp. 153-163, 2017. 
[126] L. Rittié and G. J. Fisher, "Natural and sun-induced aging of human skin," Cold Spring Harbor Perspectives in Medicine, vol. 5, no. 1, article a015370, 2015.

[127] J.-W. Shin, S.-H. Kwon, J.-Y. Choi et al., "Molecular mechanisms of dermal aging and antiaging approaches," International Journal of Molecular Sciences, vol. 20, no. 9, p. 2126, 2019.

[128] A. Kammeyer and R. M. Luiten, "Oxidation events and skin aging,” Ageing Research Reviews, vol. 21, pp. 16-29, 2015.

[129] A. C. Newby, "Dual role of matrix metalloproteinases (matrixins) in intimal thickening and atherosclerotic plaque rupture," Physiological Reviews, vol. 85, no. 1, pp. 1-31, 2005.

[130] M. Brennan, H. Bhatti, K. C. Nerusu et al., "Matrix metalloproteinase-1 is the major collagenolytic enzyme responsible for collagen damage in UV-irradiated human sking," Photochemistry and Photobiology, vol. 78, no. 1, pp. 43-48, 2003.

[131] T. He, T. Quan, Y. Shao, J. J. Voorhees, and G. J. Fisher, "Oxidative exposure impairs TGF- $\beta$ pathway via reduction of type II receptor and SMAD3 in human skin fibroblasts," Age, vol. 36, no. 3, pp. 9623-9623, 2014.

[132] R. Nigdelioglu, R. B. Hamanaka, A. Y. Meliton et al., "Transforming Growth Factor (TGF)- $\beta$ Promotes de Novo Serine synthesis for collagen production," Journal of Biological Chemistry, vol. 291, no. 53, pp. 27239-27251, 2016.

[133] S. Zhang and E. Duan, "Fighting against Skin Aging: The Way from Bench to Bedside," Cell Transplantation, vol. 27, no. 5, pp. 729-738, 2018.

[134] Y. Zhuang and J. Lyga, "Inflammaging in skin and other tissues - the roles of complement system and macrophage," Inflammation \& Allergy Drug Targets, vol. 13, no. 3, pp. 153-161, 2014.

[135] M. Bonta, L. Daina, and G. Mutiu, "The process of ageing reflected by histological changes in the skin," Romanian Journal of Morphology and Embryology, vol. 54, 3 Suppl, pp. 797804, 2013.

[136] A. G. Gunin, V. V. Petrov, N. N. Golubtzova, O. V. Vasilieva, and N. K. Kornilova, "Age-related changes in angiogenesis in human dermis," Experimental Gerontology, vol. 55, pp. 143151, 2014.

[137] A. Kennedy and R. N. Frank, "The influence of glucose concentration and hypoxia on VEGF secretion by cultured retinal cells," Current Eye Research, vol. 36, no. 2, pp. 168-177, 2011.

[138] G. K. Kolluru, S. C. Bir, and C. G. Kevil, "Endothelial dysfunction and diabetes: effects on angiogenesis, vascular remodeling, and wound healing," International Journal of Vascular Medicine, vol. 2012, Article ID 918267, 30 pages, 2012.

[139] H. Brem and M. Tomic-Canic, "Cellular and molecular basis of wound healing in diabetes," The Journal of Clinical Investigation, vol. 117, no. 5, pp. 1219-1222, 2007.

[140] J.-M. Dethy, B. Callaert-Deveen, M. Janssens, and A. Lenaers, "Determination of sorbitol and galactitol at the nanogram level in biological samples by high-performance liquid chromatography," Analytical Biochemistry, vol. 143, no. 1, pp. 119-124, 1984.

[141] E. Kubo, N. Miyoshi, M. Fukuda, and Y. Akagi, "Cataract formation through the polyol pathway is associated with free radical production," Experimental Eye Research, vol. 68, no. 4, pp. 457-464, 1999.
[142] R. Gitzelmann, "Galactose-1-phosphate in the pathophysiology of galactosemia," European Journal of Pediatrics, vol. 154, no. S2, pp. S45-S49, 1995.

[143] J. S. Meyes and L. R. Miller, "The metabolism of galactose by galactosemic fibroblasts in vitro," Biochimica et Biophysica Acta (BBA) - General Subjects, vol. 313, no. 1, pp. 9-16, 1973.

[144] G. S. Dhaunsi and M. Al-Essa, "Downregulation of insulinlike growth factor-1 via nitric oxide production in a hypergalactosemic model of neonate skin fibroblast cultures," Neonatology, vol. 110, no. 3, pp. 225-230, 2016.

[145] T. I. Slepak, M. Tang, V. Z. Slepak, and K. Lai, "Involvement of endoplasmic reticulum stress in a novel classic galactosemia model," Molecular Genetics and Metabolism, vol. 92, no. 1-2, pp. 78-87, 2007.

[146] G. T. Berry, "Is prenatal myo-inositol deficiency a mechanism of CNS injury in galactosemia?," Journal of Inherited Metabolic Disease, vol. 34, no. 2, pp. 345-355, 2011.

[147] W.-D. Jiang, L. Feng, Y. Liu, J. Jiang, and X.-Q. Zhou, "Myoinositol prevents oxidative damage, inhibits oxygen radical generation and increases antioxidant enzyme activities of juvenile Jian carp (Cyprinus carpiovar. Jian)," Aquaculture Research, vol. 40, no. 15, pp. 1770-1776, 2009.

[148] B. Liu, R. Ma, J. Zhang, P. Sun, R. Yi, and X. Zhao, "Preventive effect of small-leaved Kuding tea (Ligustrum robustum (Roxb.) Bl.) polyphenols on D-galactose-induced oxidative stress and aging in mice," Evidence-Based Complementary and Alternative Medicine, vol. 2019, Article ID 3152324, 13 pages, 2019.

[149] H. Guo, Z. Kuang, J. Zhang, X. Zhao, P. Pu, and J. Yan, “The preventive effect of Apocynum venetum polyphenols on $\mathrm{D}$ galactose-induced oxidative stress in mice," Experimental and Therapeutic Medicine, vol. 19, no. 1, pp. 557-568, 2020.

[150] J. Qian, L. Zha, B. Wang, C. Zhang, L. Hong, and W. Chen, "Synthesis, cytotoxicity and liver targeting of 3-O- $\beta$-DGalactosylated resveratrol," The Journal of Pharmacy and Pharmacology, vol. 71, no. 6, pp. 929-936, 2019.

[151] A. Dehghani, Z. Hafizibarjin, R. Najjari, F. Kaseb, and F. Safari, "Resveratrol and 1,25-dihydroxyvitamin D coadministration protects the heart against D-galactoseinduced aging in rats: evaluation of serum and cardiac levels of klotho," Aging Clinical and Experimental Research, vol. 31, no. 9, pp. 1195-1205, 2019.

[152] G. Chen, G. Ye, X. Zhang et al., "Metabolomics reveals protection of resveratrol in diet-induced metabolic risk factors in abdominal muscle," Cellular Physiology and Biochemistry : International Journal of Experimental Cellular Physiology, Biochemistry, and Pharmacology, vol. 45, no. 3, pp. 11361148, 2018.

[153] R. Sharma, M. Kumari, A. Kumari et al., "Correction to: Diet supplemented with phytochemical epigallocatechin gallate and probiotic lactobacillus fermentum confers second generation synbiotic effects by modulating cellular immune responses and antioxidant capacity in aging mice," European Journal of Nutrition, vol. 58, no. 7, pp. 2959-2960, 2019.

[154] Z. Feng, X. Hou, C. Zhu, J. Zhu, and C. Jiang, "Epigallocatechin gallate ameliorates morphological changes of pancreatic islets in diabetic mice and downregulates blood sugar level by inhibiting the accumulation of AGE-RAGE," Journal of Cellular Biochemistry, vol. 120, no. 5, pp. 8510-8520, 2018.

[155] D. Yamanaka, T. Kawano, A. Nishigaki et al., "Effects of epigallocatechin-3-gallate on systemic inflammation- 
induced cognitive dysfunction in aged rats," Journal of Anesthesia, vol. 31, no. 5, pp. 726-735, 2017.

[156] D. Chen, K. Q. Zhang, B. Li, D. Q. Sun, H. Zhang, and Q. Fu, "Epigallocatechin-3-gallate ameliorates erectile function in aged rats via regulation of PRMT1/DDAH/ADMA/NOS metabolism pathway," Asian Journal of Andrology, vol. 19, no. 3, pp. 291-297, 2017.

[157] J. A. Urrets-Zavalía, E. Espósito, I. Garay et al., "The eye and the skin in nonendocrine metabolic disorders," Clinics in Dermatology, vol. 34, no. 2, pp. 166-182, 2016. 